\title{
Agricultural Ethnography of Dieng Community: Local Knowledge of Dieng Wetan in Facing the Impact of Bun Upas on Agricultural Plants
}

\author{
Kuncoro Bayu Prasetyo ${ }^{1}$, Nurul Fatimah ${ }^{2}$, Elsa Lutmilarita Amanatin ${ }^{3}$, \\ Eka Yuniati ${ }^{4}$, Henry Sembada ${ }^{5}$ \\ \{mrbayu@mail.unnes.ac.id $\left.{ }^{1}\right\}$ \\ $1,2,3,4,5$ Universitas Negeri Semarang, Indonesia
}

\begin{abstract}
Dieng is one of the areas in Wonosobo Regency, which is located in the highlands. In majority, the Dieng people work a lot in agriculture. Many plants such as potatoes and vegetables are planted in the Dieng area. The phenomenon of bun upas or freezing of dew in the morning often occurs in Dieng throughout the dry season which is expected to reduce the temperature quite drastically to below zero degrees Celsius. This certainly has an effect on agriculture which has been damaged by the disaster. This article was written with the aim of finding out the impact of the bun upas on the sustainability of the agriculture of the Dieng Wetan community and knowing various local knowledge developed by the Dieng Wetan community in the face of the impact on the bun upas. The research was conducted with qualitative research methods and ethnographic approaches. Data collection is done through in-depth interviews, observation, and documentation. Informants in this study are the people of Dieng Wetan who worked as farmers. The results showed that: 1) The phenomenon of bun upas caused damage to several crops such as potatoes, cabbage and carica so that the farming community in Dieng Wetan suffered considerable time, energy and economic losses; 2) local knowledge developed in the Dieng Wetan community in the face of bun upas is carried out by checking the temperature every morning to the field, using sprinkle to melt the ice attached to the plants, reducing the area cultivated during the bun upas season, and developing plant species the more resistant bun upas, namely carrots. Local knowledge that develops in the farming community has not been fully able to overcome the impact of the bun upas, but at least minimizes the impacts that occur in the life of agriculture in Dieng Wetan.
\end{abstract}

Keywords: Agriculture, Bun Upas, Dieng, Ethnography, Local Knowledge

\section{Introduction}

Dieng is a plateau area in the middle of Java Island. Administratively, the Dieng Plateau is located in two regencies, Wonosobo Regency at Kejajar Disctric, and Banjarnegara Regency at Batur District. As a higland, Dieng located at an altitude of 2.093 meters above sea level, AS a tropical region, Dieng has an average cold temperature, which is around $10-15^{\circ} \mathrm{C}[1]$. The Dieng's popularity is very well-known in Indonesia as a mountain tourist area which has beautiful natural scenery and many cultural heritages or artifacts from the Ancient Mataram Kingdom in the $9^{\text {th }}$ century.

Besides being well-known as a tourist destination, Dieng is also known as a region that produce several agriculture commodities. Agriculture in the Dieng Plateau is identical to the vegetables and fruits farming, especially Potatoes, Cabbage, and Carica. Among these types of commodities, potatoes are the most dominant and widely cultivated commodity by Dieng 
farmers. Potatoes are usually planted by Dieng farmers on the slopes of hillsides, so that almost all the hilly areas are spread out potato fields. For the Dieng farmers, potatoes are an important source of their socio-economic life.

However, there is a unique annual phenomenon in Dieng which apparently greatly affects the sustainability of agriculture in Dieng, that is bun upas. Bun upas is a natural phenomenon where morning dew on leaves or in the open areas freezes because of extreme cold temperatures drop below zero degrees Celcius. The phenomenon of bun upas usually occurs during the transition period of the season, from the rainy season to dry or around the month of July to August. The appearance of bun upas is an attractive phenomenon so that many tourists come to Dieng Plateau to see it. During the appearance of Bun Upas, many tourists from various regions flocked to visit Dieng Plateau because the appearance of frosty dew that looks like a snow fields is considered a rare phenomenon in the tropics area [2].

Although it is advantageous from the tourism aspect of Dieng, the phenomenon of bun upas turns out to be a threat for agriculture in Dieng region, especially potato farming. The appearance of bun upas attached to the leaves and steam of the plant causes damage and dries the potato plants. Therefore, efforts are needed by the Dieng Wetan farming community to deal with weather change bun upas to adapt to environmental and their agriculture. The one of solution to cope with weather changes due to bun upas is with local knowledge. Local knowledge apeear due to the close connections between their livelihoods, culture, spirituality, social systems and environment [3]. From this local knowledge, the farmer ini Dieng Wetan can finish their problem and out of the impacts of climate change because "bun upas". The phenomenon due to bun upas causes farmer to suffer huge losses do tue crop failure. Therefore, this article is written with the aim to explain the impact of the bun upas on the survival Dieng community agriculture and knowing what the local knowledge was developed by the Dieng community in facing the impact of bun upas on their agricultural activities.

\section{Research Method}

This research was conducted with qualitative research methods and etnographic approaches to discover, develop, and prove a certain knowledge so that in can be used to understand, solve, and anticipate problems [4][5]. The research location was at Dieng Plateau area, precisely in Dieng Wetan Hamlet, Dieng Village, Kejajar Subdistrict, Wonosobo Regency. The Dieng Wetan Hamlet was chosen as the location of the study because this hamlet is one of the areas that most frequently experience in the phenomenon of bun upas.

The focus of this research is to find out about the impact of the phenomenon of bun upas on the sustainability of Dieng agriculture, as well as various local knowledge developed by the community to deal with the impact of this phenomenon on their agricultural activities. The study was conducted on 11th until 13th of July, 2019 by mingling and living with the Dieng Wetan Hamlet community. Primary data is obtained directly by the researcher using data collection techniques through direct observation in Dieng Wetan Hamlet, in-depth interviews with the Hamlet Head of Dieng Wetan, as well as Hamlet community and some farmers who works in the fields. There were 5 farmers interviewed in this study. Most of the farmer were interviewed is potato farmer. Data analysis was carried out using the model of Milles \& Huberman, starting from data collection, data reduction, displaying data, and making conclusions [6]. 


\section{Result and Discussion}

\subsection{Description of Dieng Wetan Hamlet}

Dieng Wetan Hamlet is a part of the Dieng Village located in Kejajar Subdistrict, Wonosobo Regency. Coordinately, the Dieng region is located in $7^{\circ} 12^{\prime} \mathrm{S}$ and $109^{\circ} 54^{\prime} \mathrm{E}$ and with an altitude of 2.565 masl (meters above sea level). In Dieng Village, there are two hamlets namely Dieng Wetan Hamlet and Kalilembu Hamlet. Seen from its location, Dieng Wetan is about $9 \mathrm{~km}$ from Kejajar Subdistrict and $26 \mathrm{~km}$ from the center of Wonosobo Regency. Dieng Wetan Hamlet is directly adjacent to Dieng Kulon Hamlet which is part of the Banjarnegara Regency area. Dieng Wetan can be accessed from several routes, such as from Banjarnegara, Batang, and Wonosobo.

The population of Dieng Wetan Hamlet amounts to 2.152 people and the majority work in agriculture, covering more than $80 \%$ of the total population. The most important agricultural commodities in Dieng Wetan are Potatoes, Cabbage and Carica. According from the data, the following are complete data on the livelihoods of the Dieng Wetan community.

Table 1. The Population of Dieng Wetan Hamlet Based on Their Livelihoods

\begin{tabular}{|c|l|c|c|}
\hline \multirow{2}{*}{ No. } & \multirow{2}{*}{ Livelihood } & \multicolumn{2}{|c|}{ Total } \\
\cline { 3 - 4 } & & Male & Female \\
\hline 1 & Farmer & 985 & 598 \\
\hline 2 & Farm Workers (hodge) & 38 & 30 \\
\hline 3 & Civil Servant & 35 & 34 \\
\hline 4 & Privat Employees & 11 & 8 \\
\hline 5 & Traders/Entrepreneur & 85 & 120 \\
\hline 6 & Other (Homestay) & 85 & - \\
\hline
\end{tabular}

(Source: The Monograph of Dieng Village, 2019)

Besides being an agricultural area, Dieng Wetan also has quite large and well-known tourism potential. There are several tourism object, such as Telaga Warna Lake and Pangilon Lake which are part of the Dieng Wetan Hamlet. In addition, the proximity to other tourist destinations in Dieng area such as the Arjuna Temple Complex, Sikidang Crater, Sikunir Hill, and various other tourist attractions make the Dieng Wetan Hamlet also crowded with tourist lodgings. Almost all houses in Dieng Wetan Hamlet has dual-function, as residence for its owners and also as homestay for tourists who stay in Dieng.

\subsection{The Phenomenon of Bun Upas in Dieng}

Bun Upas in Javanese literally means "poison dew". This was based on the fact that bun upas had the effect of damaging agricultural plants in Dieng which were effected by the bun upas. Bun upas is a phenomenon where a thin layer of ice covers the leaves at a certain temperature. Usually the bun upas phenomenon in Dieng occurs in the dry season [7]. Geographically, this phenomenon occurs because Dieng Plateau is highland area with an average temperature of 15-20 degrees Celsius and at night around 10 degrees Celsius [8]. The air temperature that reaches below zero degree celcius in the morning causes the appearance of frost which is referred to by local terms as "bun upas". 
Based on observations during the field study, the phenomenon of bun upas appeared in the early hours of the morning at around 4 a.m. and began to disappear along with the rising of the sun. According to the head of Dieng Wetan Hamlet's explanation, Pak Ali, bun upas is an annual phenomenon that appears when the dry season begins to arrive or in July-August. Bun upas can appear on a stretch of field or stick to the leaves and steams of plants. The phenomenon of bun upas does not always appear every day, but with the local knowledge, people of Dieng Wetan can recognize the signs when bun upas will appear the next day. The natural signs that interpreted by community are if in the afternoon until evening the weather always sunny and does not rain, the appearance of fog at night when the temperature begins to feel colder at night, then it can be ascertained that the bun upas will appear in the next morning.

Picture 1. The appearance of bun upas on the potato leaves

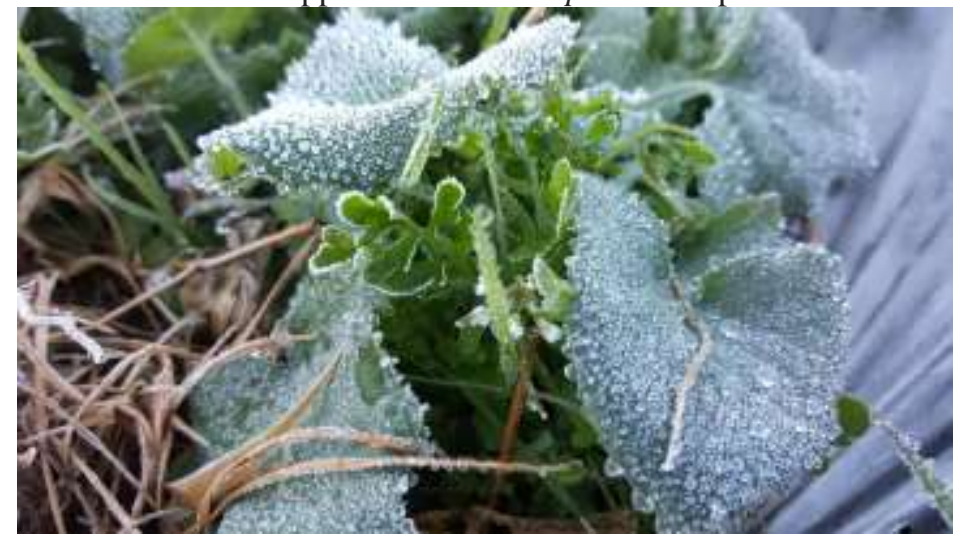

(Source: primary doc, 2019)

\subsection{The Impact of Bun Upas for Dieng Wetan Farming}

The phenomenon of bun upas gives a lot of loss for farmers, especially those in Dieng Wetan Hamlet. The direct impact from the existence of bun upas is causes some plants in the field die. According from one of the farmers information, Pak Pedi, the characteristic that arises from the destruction of plants in the field is marked by the drying of leaves and stems of plants because they are exposed from bun upas which attached to the plant causing the death plant cell tissue so that eventually the plant will withers, dries and dies. As a result of the bun upas attack, many agricultural plants have failed to harvest or die halfway. Some plants that are vulnearable to bun upas, such as potatoes, cabbage, and carica. This causes farmers to experience losses.

Picture 2. Potato plants that damaged by bun upas 


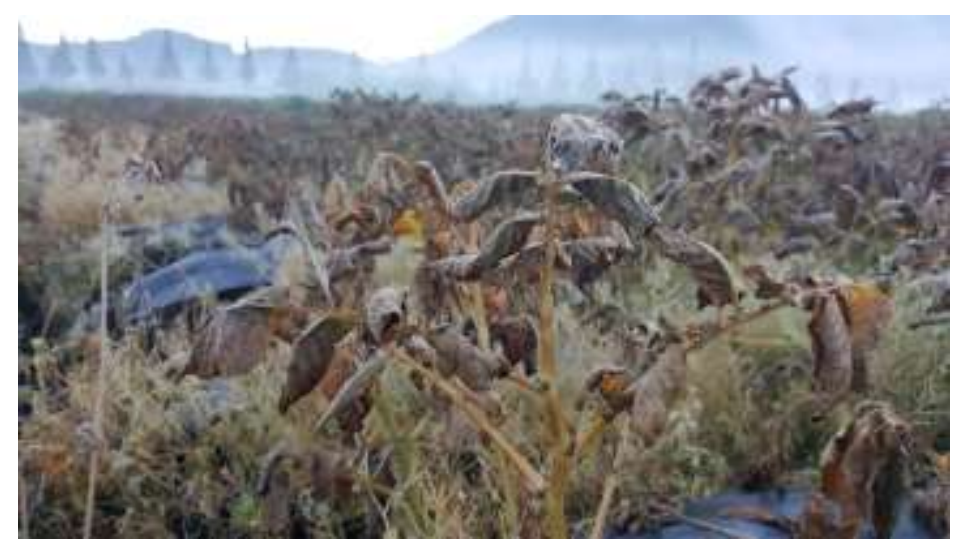

(Source: primary doc., 2019)

Potato plants are type of tube-producing vegetable that originates from family Solanaceae [9]. Potatoes usually grow on land that is at the height (the plateau). In Indonesia, potato plants are spread and grow in several highland areas, one of that in Dieng, Wonosobo Regency, Central Java. The potato plant is a spell plant and can be harvest at the age of 100 days, or about 3-4 months [10].

The results of potatoes harvested from the Dieng Plateau have a good quality with very large shapes. This commodity is also classified as providing a fairly large profit for farmers. However, due to the exsistence of bun upas, many potato plants have died. Potato plants affected but bun upas production will decrease by 50 percent. Potato farming are of 100 meters will usually haverst up to 1 ton, but if hit by bun upas it will be only harvest 500 kilograms or even less. Many potato plants do not resistant to bun upas. In Dieng, potato plants that are exposed to bun upas for ages below 50-70 days will usually die immadiately and cannot be used as seeds again. In contrast with potato plants that are more than 70 days old, they will usually be harvested directly by farmers. Therefore, usually, the potatoes that die under the age of normal (below 100 days) will have small shape.

According of the one farmer, Pak Ali, the characteristics of a potato plant that is affected by bun upas is usually began with wilting on the leaves, then the color of the leave turns yellow. The farmers in Dieng Wetan often call it with the word "gosong" or indicate that the potato plant is truly died. The dead potato plants will be replaced with new plants and with new nurseries as well. Of course, this makes farmers have to spend more as well as the repetition of the planting period from beginning.

The impact of bun upas is also happened to Carica plants which are one of the typical fruit of Dieng. In Indonesia, Carica plant only grow and bear fruit in the area of Dieng Plateau. This plant is a member of the Caricaceae family, so it has the same genus as papaya or Carica Papayae [11]. This plant grow a lot with an altitude of 1.400-2.400 meters above sea level (asl), with lace temperatures and high rainfall. This plant is also easy to die if they are exposed bun upas. Usually this plant will die immadiately after being hit by bun upas. The characteristics almost similar as those that occur in potato cultivation. Beginning with yellowing of the leaves, so that the plants become dead. Carica trees whose leaves turn yellow also will not be able to bear fruit anymore.

However, the phenomenon of bun upas that occurred in Dieng did not cause impacts or problems on the soil Dieng. Bun upas that falls on the ground only makes the soil dry. So the 
solution is only to water it with ordinary water and the soil becomes moist and can be planted again.

\subsection{Local Community Knowledge in Facing Bun Upas}

The phenomenon of bun upas is a routine thing that often happens in Dieng area toward the dry season. The Dieng farmers has understood when bun upas come, so they have various patterns of knowledge and actions as a Socio-cultural strategy in anticipating the impact of bun upas on their agricultural plants. In general, it's called local knowledge of farmer. Indigenous people born with knowledge that they have long used to adapt to environmental change, and are now using to respond to the impacts of climate change. [3]. Other opinion says that local knowledge is the reality that it bounds local culture and emerges as people's perceptions and experiences in a local environment or often referrend to as ethno-science, folk knowledge, traditional knowledge, local knowledge, people's knowledge, among others [12] [13].

Some things they do include checking the temperature every morning on potato fields, replacing plants during bun upas season, developing sprinkle systems to melt ice attached to plant, and covering plants with bamboo protection.

First, by checking the temperature and condition of the plants every morning if bun upas indicated to go down. This is an effort that is most often carried out by farmers when bun upas season occurs, farmers must wake up early and monitor whether their potato fields are covered in an up-front bun upas or not. If it turns out that the existence of bun upas is quite a lot they will take preventive measures, that is watering the land with water so that the frozen ice can be prevented or thawed immadiately.

To do the watering, Dieng farmers are developing a sprinkle system or a water sprayer that always spins watering the land. In the local term, they said sprinkle in Javanese way as Sepringkel. Sprinkle is an alternative solution that is carried out by the community by using water which is connected in pipes and taps that move in a rotating manner. The water used in the spiral is from a wellbore which is only about 8 meters above the ground. Usually, sprinkles are activated to water the potato fields at $3 \mathrm{am}$ in the morning until $9 \mathrm{am}$ in the morning so that the freezing of water that attached to the plants can be prevented or thawed. This can slightly reduce the appearance of bun upas in the leaves when the morning. However, this sprinkle system has a disadvantage because of the limited scope of land that can be sprayed, so that potatoes that are out of sprinkler coverage are still affected by bun upas.

The second attempt uses the intercropping system. Dieng farmers anticipate the impact of bun upas by planting plant uses intercropping. When entering the coming season of bun upas, the easiest adaptation strategy is to reduce the area planted with potatoes by a quarter. They then replaced land that was not planted with potatoes with other plants in the form of carrots, as well as Dieng chili which is considered more resistant to the impact of bun upas. In addition to reducing losses due to bun upas, this intercropping system is also carried out to streamline agrigultural land.

Picture 3. Intercropping System in Dieng Wetan 


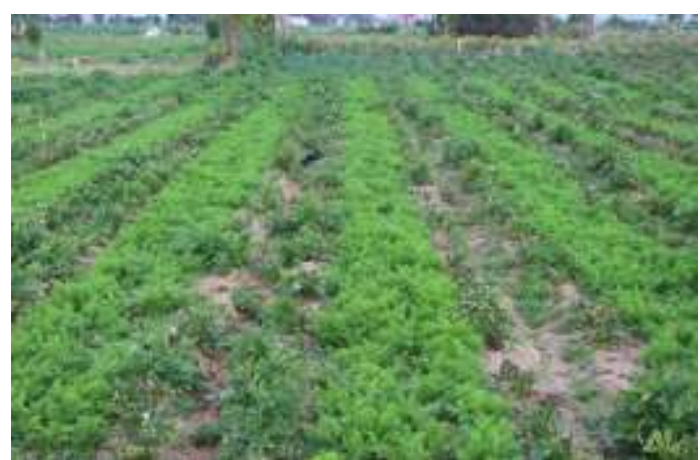

(Source: primary doc., 2019)

Therefore, various patterns of knowledge and strategies have been developed by Dieng Wetan Hamlet farmers on facing of the exsistence from bun upas such as those carried out by checking the temperature every morning to the field, using sprinkle to melt the ice attached to the plants, reducing the area cultivated during bun upas season, as well as developing plants that are more resistant from bun upas, that is carrots. However, most farmers said that until now there has not been the most effective action that the community has to eliminate the impact of bun upas on agricultural plants. As stated by the hamlet head who also work as potato farmer, Pak Ali, who said that the Dieng farmers only surrendered and truly aware that the season of bun upas arrived the production of potato agricultural would definetely decrease. The effort that they do for this is driven by the goal to reduce the impact that there is their agricultural activities can continue even though that is not an optimal.

\section{Conclusion}

The phenomenon of bun upas that occured in Dieng Wetan Hamlet caused fatal damage to agricultural plants, especially potatoes, cabbage, and carica. The damage to the plants ultimately affected Dieng Wetan farmers where they suffered economic, time, and energy losses. The Dieng Wetan farmers believe that bun upas is a natural destiny that must be accepted. However, they are also developing efforts to deal with the impact of bun upas with their traditional knowledge such as reading natural signs if the bun upas will come down, so they can protect their plants. In addition, Dieng farmers also carry out inter-change plants when the bun upas season starts, replacing some of their plants with commodities that are more resistant to bun upas attacks. The local knowledge developed by the Dieng Wetan farmers has not been fully able to overcome the impact of the bun upas, but at least it can be able to minimize the impact of the exsistence of bun upas and reduce the losses suffered. Although the treat of bun upas always happens every year, but for Dieng farmers potatoes still remain their economic mainstay.

\section{References}

[1] Https://banjarnegarakab.go.id/v3/index.php/wisata/wisata-alam, "Dataran Tinggi Dieng (Dieng Plateau)." .

[2] https://semarang.solopos.com, "Embun Upas Dieng jadi Daya Tarik Wisatawan,” 26 
Juni 2019.

[3] R. A. Ihenacho, J. . Orusha, and B. Onogu, "Rural Farmers Use of Indigenous Knowledge Systems in Agriculture for Climate Change Adaptation and Mitigation in Southeast Nigeria," Ann. Ecol. Environ. Sci., vol. 3, no. 1, pp. 1-11, 2019.

[4] L. J. Moleong, Metodologi Penelitian Kualitatif. Bandung: Remaja Rosdakarya, 2007.

[5] Soegiyono, Metode Penelitian Kualitatif. Bandung: Alfabeta, 2017.

[6] Milles and Haberman, Analisis Data Kualitatif. 1992.

[7] T. Arwiyanto, "Isolasi Bakteri Inti Es Pada Kentang," J. Perlindungan Tanam. Indones., vol. 2, no. 1, pp. 12-15, 1996.

[8] M. Noviana, "Mitigasi Bencana Untuk Pengelolaan Obyek Geowisata Plato Dieng Kabupaten Banjarnegara Jawa Tengah," Diunduh dari http//etd.repository.ugm.ac.id/, pp. 1-13, 2016.

[9] P. Kaseger, J. E. X. Rogi, and S. Tullung, "Analisis Tumbuh Tanaman Kentang (Solanum Tuberosum L) di Dataran Medium Dengan Beberapa Jarak Tanam," 2016.

[10] A. T. A. M. Putro, "Budidaya Tanaman Kentang," 2010.

[11] U. L. Magfiroh, "Faktor Ketinggian Tempat Terhadap Sintesis Vitamin Buah Carica (Carica Pubescens)," in Prosiding Seminar Nasional Pendidikan Biologi dan Biologi, 2017, no. 2011, pp. 69-74.

[12] H. Jesajas and R. Packham, "Combining Indigenous Knowledge and Agricultural Science Knowledge: A Case Study from Kisar Island, Indonesia."

[13] N. O. Adedipe, P. A. Okuneye, and I. A. Ayinde, "The Relevance of Local and Indigenous Knowledge for Nigerian Agriculture," 2004. 